\title{
Heterogeneous effects in simulating a fast nuclear reactor on the BFS test facility ${ }^{*}$
}

\author{
Yury A. Kazansky ${ }^{1}$, Gleb V. Karpovich ${ }^{1}$ \\ 1 Obninsk Institute for Nuclear Power Engineering, NRNU MEPhI, 1 Stugorodok, Obninsk, Kaluga reg., 249040, Russia \\ Corresponding author: Gleb V. Karpovich (gleb.karpovich@yandex.ru)
}

Academic editor: Georgy Tikhomirov • Received 12 August 2019 Accepted 27 October 2019 Published 10 December 2019

Citation: Kazansky YA, Karpovich GV (2019) Heterogeneous effects in simulating a fast nuclear reactor on the BFS test facility. Nuclear Energy and Technology 5(4): 345-351. https://doi.org/10.3897/nucet.5.48426

\begin{abstract}
Simulating fast neutron reactor cores for comparing experimental and calculated data on the reactor neutronics characteristics is performed using zero power test stands. The BFS test facilities in operation in Russia (Obninsk) are discussed in the present paper. The geometrical arrangement of materials in the cores of the simulated reactors (fuel pins, fuel assemblies, coolant geometry) differs from the simulation assembly on the BFS. This can cause differences between the experimental results obtained at the BFS and theoretical calculations even in the case when homogenized concentrations of all materials of the reactor are thoroughly observed. The resulting differences in neutronics parameters due to the geometry of arrangement of materials with the same homogeneous concentrations are referred to as the heterogeneous effect. Heterogeneous effects tend to increase with increasing reactor power and its size, mainly due to changes in the neutron spectra.
\end{abstract}

Calculations of a number of functional values were carried out for assessing the heterogeneous effects for different spatial arrangements of the reactor materials. The calculations were performed for the following cases: a) heterogeneous distribution of materials in accordance with the design of a fast reactor; b) heterogeneous arrangement of materials in accordance with the capabilities and design features of the BFS test facility; c) homogeneous representation of materials in the reactor core and breeding blankets.

The configuration of materials in accordance with the design data for fast reactors of the BN-1200 type was accepted as the basic calculation option, relative to which the effect called the heterogeneous shift of the functional value (HSF) was calculated. The effect of neutron leakage on the HSF obtained as the result of calculations using different boundary conditions was estimated. All calculations were carried out for the same homogeneous concentrations of all materials for all the above three configurations. Calculations were carried out as well for the case when plutonium metal fuel was used in the BFS.

The values of the following functionals were calculated for different cases of arrangement of materials: the effective multiplication factor (reactivity), the sodium void reactivity effect, the average energy of fission-inducing neutrons, and the ratios of radioactive capture cross-sections to fission cross-sections for ${ }^{239} \mathrm{Pu}$. The calculations were performed using the Serpent 2.1.30 (VTT, Finland) Monte Carlo software package for neutronics simulations and ENDF/B-VII.0 and JEFF-3.1.1 evaluated nuclear data libraries.

The effects of various options of material arrangement on the values of $k_{\mathrm{eff}}$ were found to be the greatest (about $1.6 \%$ ) for the case when fissile material in the form of dioxide is replaced with metal fissile material. Homogenization of the composition reduces the $k_{\text {eff }}$ value by about $0.4 \%$.

The average energy of fission-inducing neutrons depends to a significant extent on the leakage of neutrons and the presence of sodium (the average energy of neutrons increases and reaches in the presence of sodium about $100 \mathrm{keV}$,

* Russian text published: Izvestiya vuzov. Yadernaya Energetika (ISSN 0204-3327), 2019, n. 2, pp. 105-116.

Copyright Kazansky YA, Karpovich GV. This is an open access article distributed under the terms of the Creative Commons Attribution License (CC-BY 4.0), which permits unrestricted use, distribution, and reproduction in any medium, provided the original author and source are credited. 
that is, it increases by about 11-13\%). Replacing fissile material metal with its dioxide in the BFS test facility (while maintaining homogeneous concentrations, including that of oxygen) allows reducing the average energy of fission-inducing neutrons by about $60 \mathrm{keV}$.

The highest values of HSF, reaching $65 \%$, are observed when calculation of sodium void reactivity effect is performed with materials distributed homogeneously; however, HSF is equal to $1.5 \%$ when calculation of the reactor mock-up assembled on the BFS is performed. In the absence of neutron leakage (infinitely extended medium), the sodium void reactivity effect becomes positive and the HSF is equal to $4-7 \%$.

The heterogeneous effect of $\alpha$ for ${ }^{239} \mathrm{Pu}$ noticeably (6-8\%) depends only on the replacement of metallic plutonium with its dioxide (maintaining, of course, the homogeneous concentrations).

\section{Keywords}

Heterogeneous effect, simulation of nuclear reactors, critical test benches, fast reactor, BN, sodium void reactivity effect, neutronics calculations, Monte-Carlo

\section{The formulation of the problem}

Significant attention was devoted during the second half of the XX-th century to the experimental studies of physics of fast nuclear reactors. Along with differential measurements of cross-sections and their ratios as functions of neutron energies, integral studies performed using critical assemblies (test facilities) appeared, using which numerous integral characteristics, such as average cross-sections and their ratios, critical parameters, control rod efficiencies, spatial distributions of neutron flux density, spectral distributions of neutron flux density, etc., were obtained. Critical assemblies had different names, different design approaches were applied, but, at the same time, all the test facilities embraced the same general idea - constructing universal instruments allowing simulating fast nuclear reactor cores with different geometries, nuclear fuel compositions, compositions and volume fractions of coolants, with internal and external nuclear fuel breeding blankets at minimum financial and time expenditures. Such test facilities were constructed in the USA (ZPR, ZPPR) (Ishikawa and McKnight 2013; Lell et al. 2013), in the USSR (BFS, KOBRA) (Leypunsky et al. 1974; Rozhikhin and Semenov 2013), in France (MAZURKA) (Bouget et al. 1980), in Germany (SNEAK) (Bickel et al. 1965), in Japan (FCA) (Hirota et al. 1969), and in the Great Britain (ZEBRA) (Rowlands and Zukeran 2013). The main purpose of such test facilities was to allow creating the model of the reactor under design and obtaining, using the model, experimental values, comparison of which with calculated values allowed drawing certain conclusions with regard to the reliability and uncertainties of the design values of neutronics parameters of the modeled reactor design and entering appropriate corrections of these values in timely manner if the necessity emerged.

At present, BFS critical assemblies continue to be actively operated in Russia. Consecutive chain of research and power fast neutron reactors BR-5, BOR-60, BN-350,
BN-600, BN-800 and BN-1200 reactor currently under design were modeled using these test facilities.

Reactor mock-up assembled on the test facility differs from the real reactor structure. One of the principal differences is the geometry of arrangement of nuclear fuel, coolant and structural materials. Wish to turn critical assemblies into universal testing instruments resulted in the design where the core of the reactor to be simulated and its breeding blanket are assembled from small blocks made of different materials. Effects of the differences in the geometry of arrangement of materials while keeping the homogenous concentrations unchanged are referred to in the present study as the heterogenous effects. Significance of heterogenous effects is the larger the "softer" is the spectral-energy distribution of the neutron flux density and the larger are the dimensions of the blocks of materials used in the critical assemblies. Heterogenous structures of arrangement of materials inside the commercial reactor core and in its mock-up assembled at the BFS critical assembly are noticeably different. For nuclear fuel, the estimation of heterogeneity can be associated with the average value of the chord of the fuel pin expressed in the following form: $4 V / S$ (where $V$ is the volume of the fuel pin, $S$ is its surface area). For nuclear fuel of sodium-cooled fast reactor average chord value amounts to about $0.7 \mathrm{~cm}$; that for BFS fuel is equal for fissionable nuclei to $0.4 \mathrm{~cm}$, and for uranium-238 to $1.67 \mathrm{~cm}$. In connection with the above, significant discrepancies can be found in the cross-section blocking effects in the region of resonance neutron absorption.

The purpose of the present study is to determine using calculation method heterogenous effects in modeling large-size fast BN-type reactor core on the BFS-2 test facility by comparing the values of functionals calculated for different configurations of geometrical arrangement of materials. Besides the above, calculations were performed for defining the uncertainties of the estimations of functionals in the assumption of homogenous distribution of all materials, effects of neutron leakage and different 
representations of fissionable materials (metal or dioxide). The present study is the continuation of earlier studies. The distinguishing feature of the present study is the fact that the main emphasis is put not on the inter-comparison between heterogenous and homogenous options, but, instead, on the comparison of two heterogenous options, namely the designed reactor structure and the reactor mock-up assembled on the critical assembly, and on the obtaining the HSF values in modeling the BN-1200-type reactor on the BFS test assembly using contemporary evaluated nuclear data libraries.

Heterogenous effects for different critical assemblies were calculated, for example, in (Küsters and Pilati 1985; Le Sage et al. 1985; Bednyakov et al. 1988; Belov et al. 1989), where heterogenous effects (in the comparison with homogenous composition) reaching 3-4\% for $k_{\text {eff }}$ values were observed.

Ref. (Küsters and Pilati 1985) is the review of experimental representations of cores of designed fast reactors using test facilities of the BFS type and of calculations performed for these cores. It is noted that use of plutonium metal by the test facilities produces the $1.5 \%$ heterogenous effect for $k_{\text {eff }}$ as compared with homogenous calculation. Along with the above, the presence of heterogenous effect reaching $0.5 \%$ for $k_{\text {eff }}$ is detected as the result of transition from the plate-like structure of the reactor core implemented on the critical assemblies to the reactor design where fuel pins are used.

Reactivity coefficients for sodium-cooled fast reactors were investigated in (Le Sage et al. 1985). Noticeable heterogenous effect was observed in the comparison of homogenous and heterogenous calculations for different components of sodium void reactivity effect. It amounted to almost $110 \%$ for the spectral component, while for the total sodium void reactivity effect the heterogenous calculation produced exceedance by $138 \%$. Dependence of the spectral component of the sodium void reactivity effect on the fuel composition is noticed, with presence of ${ }^{239} \mathrm{Pu}$ and ${ }^{240} \mathrm{Pu}$ resulting in the highest sodium void reactivity effect as compared with uranium core fuel load.

Small perturbations induced by samples of materials after their introduction in the critical assembly with fast neutron spectrum were investigated in (Bednyakov et al. 1988). Central reactivity coefficients were used for estimating the above disturbances. Heterogenous effect between the homogenous and heterogenous representations amounts to $5-7 \%$.

Calculations of BFS assemblies were compared in (Belov et al. 1989) with experimental data for testing the accuracy of modeling fast reactor cores. Heterogenous effect amounted to $0.2-1.5 \%$ for the ratios of cross-sections for heavy nuclei.

Important feature of Refs. (Bednyakov et al. 1988; Belov et al. 1989) is the investigation of heterogenous effects for comparatively small dimensions of the core (approximately $50 \times 70 \mathrm{~cm}$ ), where results of the experiment were compared with homogenous and heterogenous calculations. Heterogenous effects between the two representati- ons of the reactor core (the design structure and the BFS mock-up) were not investigated in these papers.

Calculations were performed in the present study at temperature equal to $300 \mathrm{~K}$ and were implemented using the Serpent 2.1.30 (VTT, Finland) software complex (Leppänen 2015) and ENDF/B-VII.0, and JEFF-3.1.1 (Leppänen and Viitanen 2013) evaluated nuclear data libraries provided along with the software complex.

\section{Selected functionals and calculation models}

One of the most important functionals is the effective neutron multiplication factor determining the reactivity margin which is sought to be made as low as possible. From the viewpoint of nuclear safety, it would be good to have the reactivity margin less than the effective fraction of delayed neutrons. Such problem is addressed in the design project of BREST-300 reactor (Orlov et al. 2003).

Average energy of fission-inducing neutrons is the important integral indicator for fast reactors. It is determined in the Serpent software complex as the arithmetic mean of energies of neutrons inducing fission of any nuclide.

Sodium void reactivity effect is the extremely important functional for estimating nuclear reactor safety features. Sodium void reactivity effect is significantly sensitive to its components, since it is the algebraic sum of the components producing effects with different signs - spectral, absorption and leakage components. The values of these components vary not proportionally when sodium is evacuated from the reactor core. Moreover, the sign of sodium void reactivity effect depends on the fuel composition and neutron leakage (Hammel and Okrent 1975).

Breeding of fissionable materials depends to a considerable extent on the ratio of radiation absorption cross-section to fission cross-section $\alpha$, measurement of which proves to be a complex enough problem. It is advisable to investigate the heterogenous effect for this functional as well.

In order to calculate the heterogenous effect due to the difference between the arrangement of materials in comparison with its counterpart in the design documentation, it is necessary to obtain the values of functionals for the following calculation models.

M1. Cell of the fuel assembly model with neutron leakage. Complete reactor core with all functional zones is modeled. "Black boundary" conditions, i.e. absorption of neutrons escaping the reactor core boundaries, is preset on the external boundaries of the functional zones. The calculation cell in this model and its dimensions are shown in Fig. 1. Dimensions of fuel assemblies and of fuel pins were designed on the basis of the data for BN-1200 reactor (Fast neutron reactors, Shepelev 2015), which allowed obtaining the ratios between the volume fractions of fuel, coolant and structural materials (Table 1). Since the purpose of the present study is the 
comparison of heterogenous effects between the actual arrangement of materials in the fuel assembly and the reactor mock-up implemented on the BFS critical assembly, more accurate compliance with $\mathrm{BN}-1200$ reactor parameters is required.

M2. Homogenized model of fuel assembly cells with neutron leakage. Complete reactor core with all functional zones is modeled. The model differs from model M1 (fuel assembly with neutron leakage) only by the homogenous representation of the arrangement of materials.

M3. Model of BFS cells with metal fuel load with neutron leakage. Complete reactor core with all functional zones is modeled. The mock-up is assembled in the representation, which can be realized on the BFS test facility by using small blocks containing different materials. Similar to model M1 "black boundary" conditions are preset on external surfaces of the modeled system. Calculation cell in this model and its dimensions (Rozhikhin and Semenov 2013) are shown in Fig. 2; part of vertical section of the model with geometrical parameters of the blocks (Rozhikhin and Semenov 2013) is shown in Fig. 3. Plutonium metal in the form of ring-shaped gaskets with mass of about $125 \mathrm{~g}$ in steel cladding is used in the model. Oxygen occupies the intertubular space (remaining after placement of steel rods) and the free space in the gaskets consisting of plutonium.

M4. Model of BFS cells with dioxide fuel load and with neutron leakage. Corresponds to the metal-loaded BFS model; however, mixed uranium and plutonium oxides loaded in small blocks intended for loading plutonium metal and for loading uranium dioxide are used instead of plutonium metal. The difference between models M3 and M4 is illustrated in Fig. 4.

Calculations were performed in order to establish the effects of neutron leakage on the HSF values for each of the models in the conditions of infinitely extended medium with composition corresponding to the compositions of

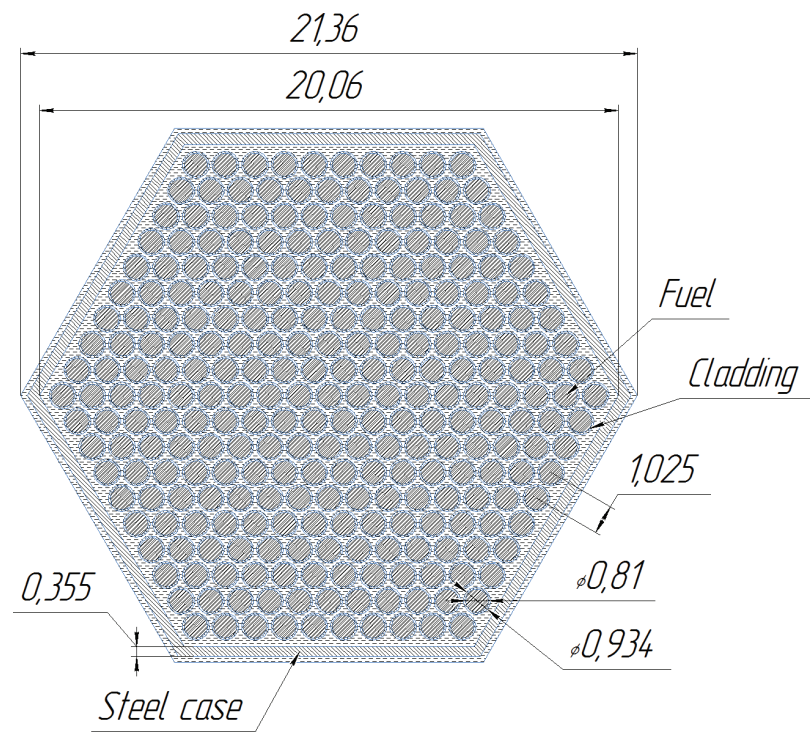

Figure 1. Fuel assembly model. Active part (all dimensions are in $\mathrm{cm}$ ).
Table 1. Volume fractions of materials in different parts of the fuel assembly.

\begin{tabular}{l|c|c|c}
\hline \multicolumn{1}{c|}{ Fuel assembly section } & Na & Steel & $\mathbf{U O}_{2}+\mathbf{P u O}_{2}$ \\
\hline Lower gas void & 0.298 & 0.231 & - \\
& $(0.97)$ & $(7.85)$ & \\
\hline Active section (AS), Lower axial blanket & 0.298 & 0.231 & 0.471 \\
(LAB) & $(0.97)$ & $(7.85)$ & $(9.2$ in the AS) \\
& & & $(9.5$ in the LAB) \\
\hline Sodium void & 0.923 & 0.077 & - \\
& $(0.97)$ & $(7.85)$ & \\
\hline
\end{tabular}

Note: volume, \%; density values in the brackets, $\mathrm{g} / \mathrm{cm}^{3}$

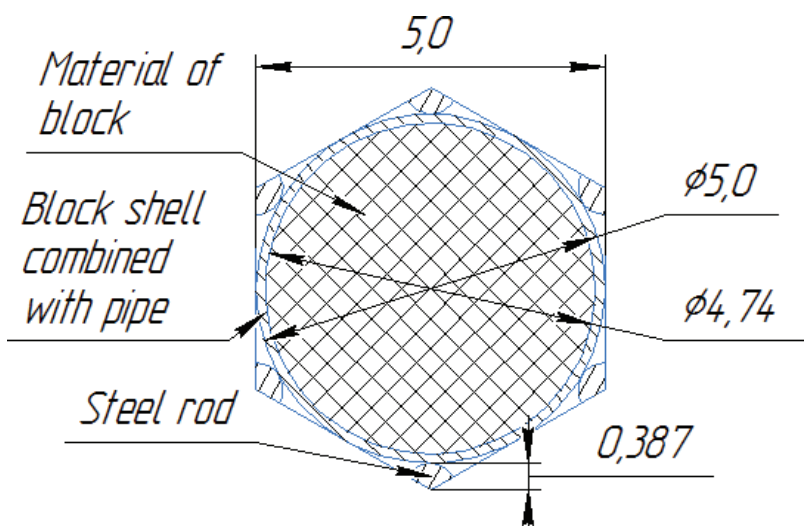

Figure 2. Cross-section of the BFS cell (all dimensions are given in $\mathrm{cm}$ ).

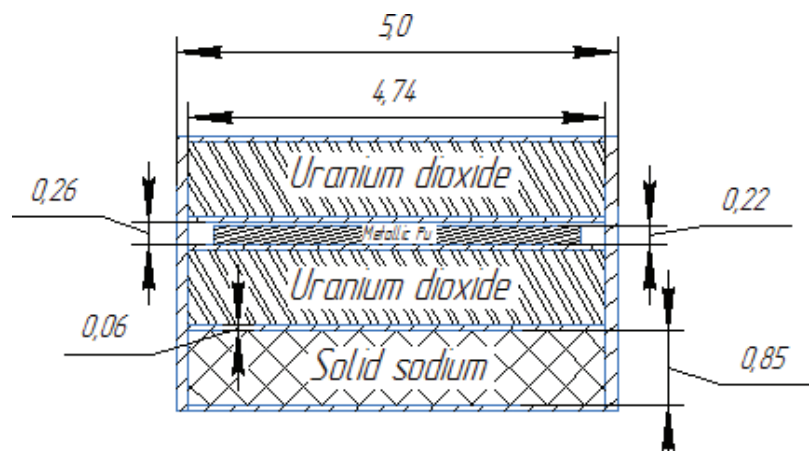

Figure 3. Part of vertical section of the metal-loaded BFS cell (all dimensions are given in $\mathrm{cm}$ ).

cores for the options M1 - M4. Calculation models of the core without neutron leakage are indicated as $\mathrm{M} 1^{\infty}-\mathrm{M} 4^{\infty}$.

The so-called "low-background" plutonium (95.17\% ${ }^{239} \mathrm{Pu}, 4.58 \%{ }^{240} \mathrm{Pu}, 0.25 \%{ }^{241} \mathrm{Pu}$ ) (Rozhikhin and Semenov $2013)$ and "high-background" plutonium $\left(90 \%{ }^{239} \mathrm{Pu}, 9 \%\right.$ $\left.{ }^{240} \mathrm{Pu}, 1 \%{ }^{241} \mathrm{Pu}\right)$ compositions are used in modeling fast reactors using BFS test facilities. "High-background" plutonium with composition containing $9 \%$ of ${ }^{240} \mathrm{Pu}$ and $1 \%$ of ${ }^{241} \mathrm{Pu}$ along with ${ }^{239} \mathrm{Pu}$ was chosen as the model composition. Calculations were performed for $\mathrm{M} 1_{\mathrm{HB}}-\mathrm{M} 4_{\mathrm{HB}}$ models, which differed from models M1 - M4 only by the use of "high-background" plutonium instead of power reactor grade plutonium $\left(1 \%{ }^{238} \mathrm{Pu}, 66 \%{ }^{239} \mathrm{Pu}, 26 \%{ }^{240} \mathrm{Pu}, 3 \%\right.$ ${ }^{241} \mathrm{Pu}, 2 \%{ }^{242} \mathrm{Pu}, 2 \%{ }^{241} \mathrm{Am}$ ) for the purpose of establishing the effect of plutonium isotopic composition on the HSF. 

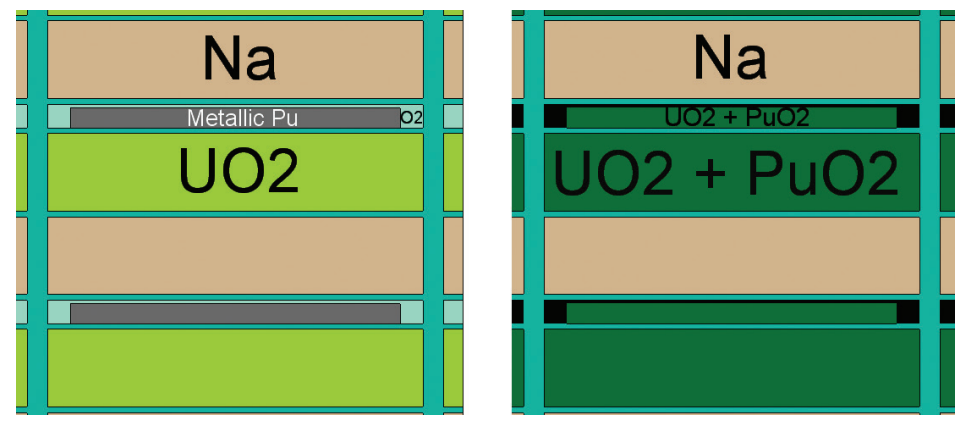

Figure 4. Calculation setup for BFS-metal model (left) and for BFS-dioxide model (right).

Plutonium is used on BFS test facilities in the form of $\mathrm{Pu}$ metal ring-shaped gaskets. At the same time, nuclear fuel in reactors is mainly used in the form of dioxide. Therefore, HSF values were calculated, as well, for the case of use of fuels in the BFS mock-ups in the form of pellets consisting of plutonium metal. Calculations were performed for establishing the effects produced on the HSF values with replacement of fuel pellets made of $\mathrm{PuO}_{2}$ with plutonium metal pellets and respective amount of oxygen.

Volume fractions of different materials (fuel, coolant, structural materials) for different functional zones of the reactor are presented in Table 1 . These values were first used for calculating isotopic compositions in the functional zones of the reactor in the homogenized representation. Following this, the obtained homogenous compositions were used for creating the heterogenous models corresponding to the design of the BFS text facility and, therefore, the densities of the materials had to be adjusted in such a way, as to maintain the same number of nuclei of each of the nuclides per unit volume of the model as that for the homogenous composition.

\section{Results of calculations and discussion}

Heterogenous shifts of functionals presented in Tables $2-4$ were determined in the calculations performed for each of the functionals as follows:

$$
\operatorname{HSF}\left(\Phi_{i}\right)=\left(\Phi_{i, \mathrm{BFS}} / \Phi_{i, \mathrm{FS}}\right)-1
$$

where $\Phi_{i, \mathrm{FA}}$ is the value of the functional calculated for the arrangement of the material according to the geometry corresponding to the reactor structure design; $\Phi_{i, \mathrm{BFS}}$ is the value of the functional calculated for the arrangement of the material according to the geometry corresponding to the BFS-2 structure. Since concentrations of materials in the reactor core and in the BFS reactor mock-up were maintained the same, the differences between the functionals for the reactor and the reactor mock-up were explained by the different heterogenous arrangements of materials.
Values of HSF functionals calculated using the algorithm above are presented as well in each of the tables for the case of homogenous distribution of materials:

$$
\operatorname{HSF}\left(\Phi_{i}\right)=\left(\Phi_{i, \mathrm{HOM}} / \Phi_{i, \mathrm{FA}}\right)-1,
$$

$\Phi_{i, \mathrm{HOM}}-$ is the value of the functional calculated for homogenous distribution of the materials.

HSF associated with homogenous distribution of materials provides the insight on the scale of uncertainties in engineering calculations not overburdened with fine details in the representation of structures of fuel pins and fuel assemblies.

Results of calculations of HSF values relative to the arrangement of materials is the design of the reactor fuel assemblies for different functionals and for three options of representation of the calculation conditions are presented in Table. For all the results of calculations the relative uncertainty including the uncertainties of the data from evaluated nuclear data libraries was equal to $\Delta k_{\text {eff }}=0.13 \%$.

Let us note the following features of the obtained results.

HSF for the sodium void reactivity effect for the case of homogenous distribution of materials was found to be very high $(-65 \%)$, and, therefore, calculating sodium void reactivity effect in homogenous representation is senseless. At the same time, HSF for the sodium void reactivity effect in heterogenous BFS compositions was found to be within the limits of $1.5 \%$. This means that heterogenous compositions of fuel assemblies of BFS cells appear to be interchangeable enough in the calculations of sodium void reactivity effect. Shifting due to the heterogenous effect in the $k_{\text {eff }}$ value by $0.4 \%$ leads to the change of reactivity margin by $10 \%$ (if the reactivity margin is equal to $4 \%$ ).

Table 2. HSF values for the reactor loaded with plutonium metal taking into account neutron leakage.

\begin{tabular}{l|c|c|c|c}
\hline \multicolumn{1}{c|}{ Functional } & \multirow{2}{*}{ M1 model } & \multicolumn{3}{|c}{ HSF } \\
\cline { 3 - 5 } & & $\begin{array}{c}\text { M1 and M2 } \\
\text { models }\end{array}$ & $\begin{array}{c}\text { M1 and M3 } \\
\text { models }\end{array}$ & $\begin{array}{c}\text { M1 and M4 } \\
\text { models }\end{array}$ \\
\hline $\mathrm{K}_{\text {eff }}$ & 1.1167 & $-0.39 \%$ & $+1.45 \%$ & $+0.45 \%$ \\
& & $(1.1123)$ & $(1.1329)$ & $(1.1217)$ \\
\hline Average energy of "fission- & 807 & $-0.87 \%$ & $+7.93 \%$ & $+0.37 \%$ \\
inducing" neutrons & & $(800)$ & $(871)$ & $(810)$ \\
\hline Sodium void reactivity effect & -0.00783 & $-65 \%$ & $+1.15 \%$ & $+1.53 \%$ \\
& & $(-0.00274)$ & $(-0.00792)$ & $(-0.00795)$ \\
\hline$\alpha{ }^{239} \mathrm{Pu}$ & 0.295 & $0 \%$ & $-8.14 \%$ & $-0.34 \%$ \\
& & $(0.295)$ & $(0.271)$ & $(0.294)$ \\
\hline
\end{tabular}


Table 3. HSF for reactor models without neutron leakage and power reactor-grade plutonium.

\begin{tabular}{l|c|c|c|c}
\hline \multicolumn{1}{c|}{ Functional } & \multirow{2}{*}{\begin{tabular}{c} 
M1 \\
\cline { 3 - 5 }
\end{tabular}} & $\begin{array}{c}\mathbf{M}^{\infty} \text { and } \\
\text { model }^{\infty} \text { models }\end{array}$ & $\begin{array}{c}\text { M1 }{ }^{\infty} \text { and } \\
\text { M3 }^{\infty} \text { models }\end{array}$ & $\begin{array}{c}\text { M1 }^{\infty} \text { and } \\
\text { M4 }^{\infty} \text { models }\end{array}$ \\
\hline $\mathrm{k}_{\text {eff }}$ & 1.2860 & $-0.58 \%$ & $+1.94 \%$ & $+0.12 \%$ \\
& & $(1.2785)$ & $(1.3109)$ & $(1.2875)$ \\
\hline Average energy of "fission- & 744 & $-0.67 \%$ & $+6.72 \%$ & $-0.27 \%$ \\
inducing" neutrons, keV & & $(739)$ & $(794)$ & $(742)$ \\
\hline Sodium void reactivity effect & +0.02894 & $+7.74 \%$ & $-4.28 \%$ & $-7.50 \%$ \\
& & $(+0.03118)$ & $(+0.02770)$ & $(0.02677)$ \\
\hline$\alpha^{239} \mathrm{Pu}$ & 0.3023 & $-0.10 \%$ & $-6.81 \%$ & $+0.23 \%$ \\
& & $(0.3020)$ & $(0.2817)$ & $(0.3030)$ \\
\hline
\end{tabular}

Table 4. HSF for reactor mock-ups with neutron leakage and high-background plutonium load.

\begin{tabular}{|c|c|c|c|c|}
\hline \multirow[t]{2}{*}{ Functional } & \multirow[b]{2}{*}{$\begin{array}{l}\text { M1 }_{\mathrm{HB}} \\
\text { model }\end{array}$} & \multicolumn{3}{|c|}{ HSF } \\
\hline & & \begin{tabular}{|c|} 
M1 $1_{\mathrm{HB}}$ and \\
$\mathrm{M} 2_{\mathrm{HB}}$ models
\end{tabular} & \begin{tabular}{|c|} 
M1 $_{\mathrm{HB}}$ and \\
$\mathrm{M} 3_{\mathrm{HB}}$ models
\end{tabular} & $\begin{array}{c}\text { M1 }{ }_{\mathrm{HB}} \text { and } \\
\text { M4 }{ }_{\mathrm{HB}} \text { models }\end{array}$ \\
\hline $\mathrm{k}_{\mathrm{eff}}$ & 1.2493 & $\begin{array}{l}-0.28 \% \\
(1.2458)\end{array}$ & \begin{tabular}{|l|}
$+1.06 \%$ \\
$(1.2626)$
\end{tabular} & $\begin{array}{l}+0.46 \% \\
(1.2551)\end{array}$ \\
\hline $\begin{array}{l}\text { Average energy of "fission- } \\
\text { inducing" neutrons, } \mathrm{keV}\end{array}$ & 748 & $\begin{array}{c}-0.67 \% \\
(743)\end{array}$ & $\begin{array}{c}+8.29 \% \\
(810)\end{array}$ & $\begin{array}{l}+0.53 \% \\
(752)\end{array}$ \\
\hline Sodium void reactivity effect & -0.00844 & $\begin{array}{c}-53.4 \% \\
(-0.00393)\end{array}$ & $\begin{array}{c}+8.18 \% \\
(-0.00913)\end{array}$ & $\begin{array}{c}+2.61 \% \\
(-0.00866)\end{array}$ \\
\hline$\alpha{ }^{239} \mathrm{Pu}$ & 0.2787 & $\begin{array}{l}+0.18 \% \\
(0.2792)\end{array}$ & $\begin{array}{l}-8.32 \% \\
(0.2555)\end{array}$ & $\begin{array}{l}-0.39 \% \\
(0.2776)\end{array}$ \\
\hline
\end{tabular}

HSF for all functionals calculated for M1 and M4 models reached $1.5 \%$ only for the values of sodium void reactivity effect; for all remaining cases, the values of HSF are within the limits of $\pm 0.5 \%$.

HSF values were found to be sensitive to the variation of chemical structure of plutonium (replacement of plutonium dioxide with plutonium metal) and, as the consequence, to the noticeably high HSF values when calculations are performed for M1 and M3 models. Here, HSF value for the average value of fission-inducing neutrons was found to be equal to $+8 \%$; and that for the $\alpha$ value - to $-8 \%$. The latter result must be taken into consideration, since the breeding gain is very sensitive to $\alpha$-values.

Neutron leakage affects the HSF values. Estimation of this effect was made on the basis of comparison of results of calculations for $\mathrm{M} 1^{\infty}-\mathrm{M} 4^{\infty}$ models (see Table 3 ).

In the case of absence of neutron leakage (infinitely extended core) and homogenous material composition (M1 ${ }^{\infty}$ and $\mathrm{M} 2^{\infty}$ models) the highest HSF value corresponded to sodium void reactivity effect (about 7\%). The highest HSF values were registered for all functionals in the case when plutonium is represented in the form of metal pellets in the calculation model of the BFS mock-up.

Results of calculations of HSF with high-background plutonium are presented in Table 4.

Under similar calculation conditions, significant change of plutonium isotopic composition very weakly influenced the HSF values with exception of HSF for sodium void reactivity effect for the BFS mock-up with plutonium metal load. This can be seen from the comparison of results in Tables 2 и 4. Evidently, increase of HSF when plutonium metal is used is associated with different conditions of blocking of ${ }^{240} \mathrm{Pu}$ cross-sections.

\section{Conclusion}

1. The implemented studies allow formulating the following conclusions confirmed by quantitative estimations. Modeling nuclear reactors is conducted on critical assemblies with heterogenous structure, which is different from the structure of the reactor under design. This difference (formulated in terms of HSF) caused by the differences in the arrangement of materials will influence the shifting of values of the calculated functionals. However, as it was demonstrated by the performed calculations, if similar structure of materials is used (dioxide in the case under examination instead of "spreading" separated plutonium metal and oxygen over the calculation cell), then the HSF values for all selected functionals are found in the case of power reactor-grade plutonium to be within the limits from $-3 \%$ to $+1.5 \%$, while the real uncertainty for $k_{\text {eff }}$ caused by the uncertainties for masses, fuel enrichment and density values, fuel pin dimensions and ratios of volumes of fuel, coolant and structural materials, etc., amounts to approximately $0.5 \%$ (Rozhikhin and Semenov 2013). The main conclusion is that different arrangements of materials in the fuel assemblies of the reactor and the reactor mockup weakly influence the HSF values if materials with similar molecular structure are used.

2. Somewhat larger HSF values $( \pm 8 \%)$ were obtained for the situation when plutonium metal is used on the BFS test facility, which affects the HSF values for the functionals significantly depending on the spectral distribution of neutrons (ratio of cross-sections and average value of energies of neutrons inducing fissions of nuclei). Values of HSF for sodium void reactivity effect and $k_{\text {eff }}$ remained at the same level of $1.5 \%$.

3 . For the simplest (engineering) calculations when homogenous distributions of materials are used, estimations of effects of detailed description of fuel assemblies and fuel pins on the HSF values were assessed. It was determined that for all functionals except sodium void reactivity effect HSF values do not exceed one percent (compare calculated results obtained for models M1 and M2 with different boundary conditions and different plutonium isotopic compositions). It makes sense to further justify this conclusion by extending the set of functionals thus enhancing the rating of engineering calculations. However, calculation of sodium void reactivity effect with neutron leakage is not applicable without taking into account the heterogenous structure (without correct accounting for neutron leakage).

\section{Acknowledgements}

Authors express their gratitude to Professor V.A. Dulin and Associate Professor G.M. Pshakin for their comments and suggestions referring to the specific features of modeling using BFS test facilities. 


\section{References}

- Bednyakov SM, Golubev BN, Dulin VA, Kozlovtsev VG, Mamontov VF (1988) Experimental justification of methods for assessing the critical perturbations of fast assemblies with small samples. Atomnaya Energiya 65(6): 426-430. [in Russian] https://doi. org/10.1007/BF01122474

- Belov SP, Dulin VA, Zhukov AV, Kuzin EN, Mozhaev EK, Sitnikov NI, Tsibulya AM, Shapar AN, Seifert E, Kuntsman B, Heinzelman B (1989) Effects of small heterogeneity of fast critical assemblies. Atomnaya Energiya 66(1): 13-17. [in Russian] https://doi. org/10.1007/BF01121066

- Bickel W, Engelmann P, Wittek G (1965) Safety Report for the Fast Zero-Power Arrangement Karlsruhe SNEAK. Nuclear Research Center Karlsruhe, Karlsruhe, 353 pp.

- Bouget Y, Hammer P, Periot R, Kazansky Yu (1980) Etude d'interaction de barre dans les assemblages critiques BFS-24-16 (Obninsk) et MASURKA (Kadarache). Fast Reactor Physics (IAEA), 21-38.

- Fast neutron reactors BN-1200 (2019) Fast neutron reactors. BN-1200. https://www.ippe.ru/nuclear-power/fast-neutron-reactors/122-bn1200-reactor [accessed May 21, 2019; in Russian]

- Hammel G, Okrent D (1975) Reactivity Coefficients in Large Fast Nuclear Reactors. Atomizdat Publ., Moscow, 69-106. [in Russian]

- Hirota J, Nomoto S, Hirakawa N, Nakano M (1969) Studies of the criticality of $20 \%$ enriched uranium fast critical assemblies (FCA-I). Nuclear Science and Technology 6: 35-42. https://doi.org/10.1080/1 8811248.1969.9732831

- Ishikawa M, McKnight RD (2013)ZPPR-10A Experiment: a 650 MWeclass Sodium-Cooled MOX-fueled FBR Homogeneous Core Mock-Up Critical Experiment with Two Enrichment Zones and Nineteen Control Rod Positions. ZPPR-LMFR-EXP-001. International Handbook of Evaluated Reactor Physics Benchmark Experiments, NEA OECD.

- Küsters H, Pilati S (1985) The present accuracy of physics characteristics of unirradiated fast reactor cores. Progress in Nuclear Energy 16(3): 201-229. https://doi.org/10.1016/0149-1970(85)90009-5
- Le Sage LG, Lineberry MJ, McFarlane HF (1985) Current status of fast reactor physics reactivity coefficients. Progress in Nuclear Energy 16(3): 231-250. https://doi.org/10.1016/01491970(85)90010-1

- Lell RM, Morman JA, Schaefer RW, McKnight RD (2013) ZPR6 Assembly 7 Experiments: a Fast Reactor Core with Mixed $(\mathrm{Pu}, \mathrm{U})$-Oxide Fuel and Sodium with a Thick Depleted Uranium Reflector. ZPR-LMFR-EXP-001. International Handbook of Evaluated Reactor Physics Benchmark Experiments, NEA OECD.

- Leppänen J (2015) Serpent - a Continuous-Energy Monte Carlo Reactor Physics Burnup Calculation Code. User's Manual. VTT Technical Research Centre of Finland.

- Leppänen J, Viitanen T (2013) Cross Section Libraries for Serpent 1.1.7., Espoo, VTT Technical Research Centre of Finland, 58 pp.

- Leypunsky AI, Orlov VV, Kazansky YuA, Zinoviev VP, Ukraintsev FI, Shapar AV, Klintsov NA (1974) BFS-1 complex - a microtron for studying the neutron spectra of fast reactors. Atomnaya Energiya 36(1): 3-5. [in Russian] https://doi.org/10.1007/ BF01123094

- Orlov VV, Smirnov VS, Filin AI (2003) Deterministic safety of BREST reactors. Energiya, Ekonomika, Tekhnologiya, Ecologiya 10: 13-20. [in Russian]

- Rowlands J, Zukeran A (2013) The ZEBRA MOZART Programme. ZEBRA-LMFR-EXP-002. International Handbook of Evaluated Reactor Physics Benchmark Experiments, NEA OECD.

- Rozhikhin Y, Semenov M (2013) BFS-61 Assemblies: Critical Experiments of Mixed Plutonium, Depleted Uranium, Graphite and Lead with Different Reflectors. BFS1-LMFR-EXP-002. International Handbook of Evaluated Reactor Physics Benchmark Experiments, NEA-OECD.

- Shepelev SF (2015) Technical design of the BN-1200 reactor. http://www.innov-rosatom.ru/files/articles/b4589ee208b5b20af9c07c28921d4891.pdf [accessed May 21, 2019; in Russian] 